\title{
Practice research on community micro renewal from the perspective of healthy community
}

\author{
Li XIN, Beijing Forestry University, China \\ Liao DANYAN, Beijing Forestry University, China
}

\begin{abstract}
With the acceleration of urbanization and the frequent occurrence of residents' physical and mental health problems, public health has become one of the most important factors in urban development. And building healthy communities is an effective measure to improve public health. In the context of smart growth planning, community renewal is an important part of building healthy communities. To a certain extent, introducing the concept of healthy city into community micro-renewal can promote residents' physical and mental health and social equity, among which we introduce the method of health impact assessment. Community health impact assessment points of three stages, including micro update assessment preparation, project evaluation analysis and implementation, in order to determine the factors affecting health, the health improvement measures and the results of evaluation, planning and design projects to residents health gain role play to the largest. This Assessment implementation mobilized public participation, strengthen the cooperation of the parties, also let residents pay attention to health problems. Taking the renewal of public space in Dashilan community courtyard as an example, this paper explores the application of health impact assessment in practical projects and summarizes the shortcomings in practice. It is a new exploration to introduce the concept of healthy community in community microrenewal, which provides new ideas for building healthy cities and improving public health in China.
\end{abstract}

\section{Keywords}

healthy community, public health, community micro-renewal, Dashilan area, green space of courtyard

With the continuous advancement of urbanization process, the urbanization rate has been growing rapidly. At present, the urbanization rate in China has reached $60 \%$, and 9 large cities have now already reached the standard of high-density cities in the world. Rapid urbanization drives the development of regional economy and bring convenient life at the same time, also, the declination of the environment quality, people's quality of life falling, housing tension, 'city diseases' such as traffic congestion and the resulting, urban residents' physical and mental health problems, such as the incidence of chronic diseases and mental illness and mortality rapidly(Figure 1). In a word public health become an important and indispensable factor in urban development. 


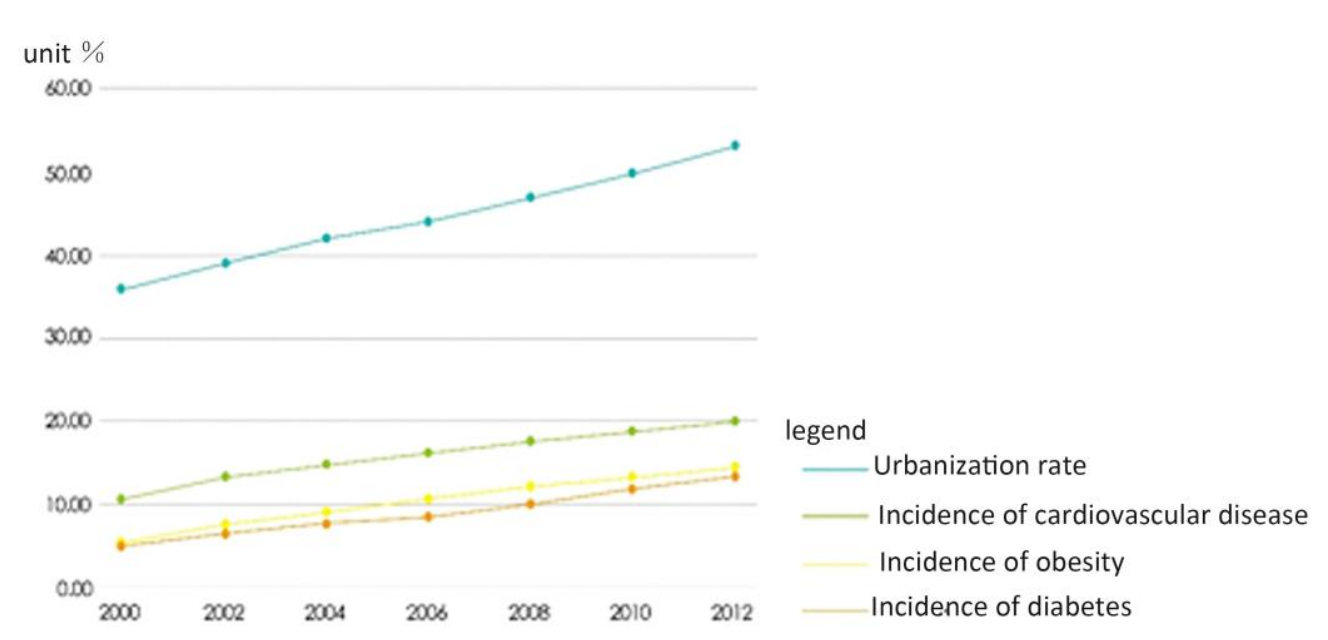

Figure 1. Line chart of urbanization rate and disease incidence from 2000 to 2012.

\section{A brief introduction to healthy communities and community renewal}

\subsection{Healthy Communities}

In 1985, the World Health Organization (WHO) put forward the concept of 'healthy city' in the Ottawa Charter of Health Promotion, hoping to achieve a healthy state of society, body and mind through effective environmental support and service measures. It is a spatial intervention strategy oriented at disease prevention and public health promotion. As early as 30 years ago, China has introduced healthy city as an advanced policy experience and applied it to the construction of public health resources. As far as landscape architecture is concerned, it's planning and intervention on urban public space environmental resources are less.

As one of the areas closely related to people in urban life, community is the public space that people have the most frequent contact with and the platform for People's Daily sports, entertainment and communication. And the healthy community is one of the manifestations of healthy city. In the 'Health determinants Model' proposed by WHO in 1997, it was mentioned that society and community are one of the determinants of health (Figure 2). Canada has tried to carry out the construction of the healthy community in the early 1980's, and after decades of development and research, more than 3000 communities in more than 50 countries have made their efforts on exploration and construction of healthy community, which let its status in urban planning and design grow these years. In the sixth stage (2014-2018) of the healthy city construction, European will take 'create resilient communities and supportive environment' as the theme.

From the perspective of landscape architecture, healthy communities are to create an environment with ecological benefits and beautification function for the public, thus affecting people's physical and mental health. Community public space is carrying residents daily traffic, physical exercise and a variety of functions of social communication. Health of the community environment is both reasonable and beautiful roads public space design and space design, green courtyard space design. And it can promote the convenience degree of residents, safe, pleasant and beautiful environment will stimulate people to outdoor sports and leisure activities, choose to walk or cycle independently, and increase happiness index. Natural scenery can relieve physical and mental stress, purify the mind, and reduce the mortality rate of cardiovascular diseases. Older residents living near green streets have a longer life span and a better quality of life than older residents living in ordinary communities. The lower the proportion of 
cardiovascular and cerebrovascular diseases and type 2 diabetes in residents living in green areas.

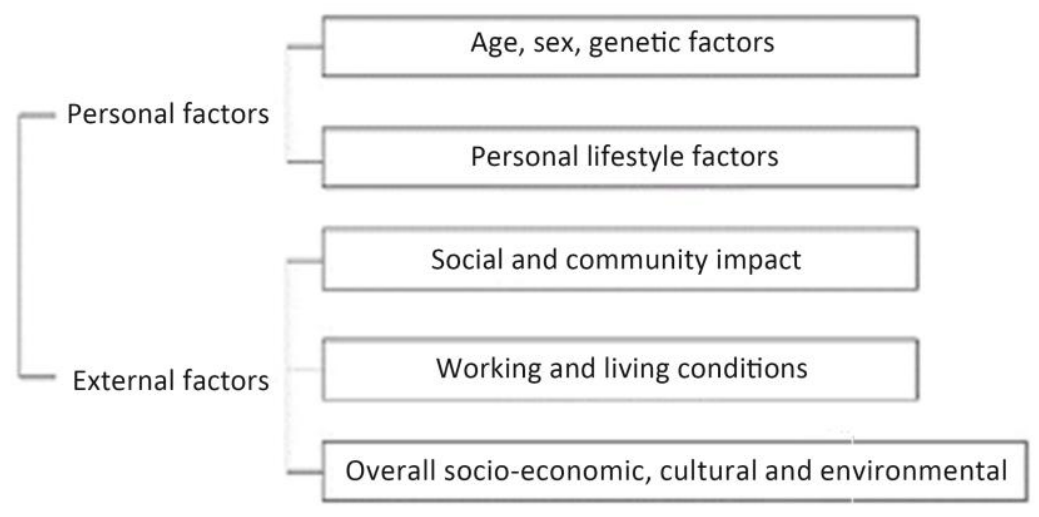

Figure 2. Health determinants model.

\subsection{Community micro renewal}

Under the background of stock planning and smart growth theory, cities have changed from extensive expansion to connotative development, and community construction has changed from quantitative change to qualitative change. Community renewal has become an important part of community construction at home and abroad. How to analyze the health status and influence factors of the old community through an effective evaluation system, update and activate the community, stimulate the community vitality, optimize the neighborhood relationship, beautify the community environment, and create a safe and harmonious space, has become an important link in the construction of healthy community.

In recent years, China has gradually attached importance to community micro renewal, such as Beijing's Baita Temple renewal plan, Dashilan renewal plan, Huayuan road street community children's playground renewal, Tiantongyuan community public space renewal, etc. The research mainly presents as exploratory single case and public participation oriented upgrading. On the whole, the systematic research of community micro renewal is still in the exploratory stage. Considering public health and creating a healthy community environment is the future development trend and the research focus of this paper.

\section{Application of health impact assessment system}

\subsection{Overview of health impact assessment}

Health Impact Assessment (HIA) is an evidence-based decision-making methodology developed by the World Health Organization (WHO) in the Gordon Burg Common Protocol. It is derived from the Environmental Impact Assessment (EIA). As a practical tool, HIA has received increasing attention abroad. Since its origin in European countries in the 1980s, HIA has been carried out practical research in Europe, the United States, Africa and the Asia-Pacific region. It enables decision makers, citizens and designers to participate in the planning and design process from the perspective of health, and make suggestions on the potential impact of health. Therefore, it can better carry out public participation. It is a new trend to use health impact assessment tools in planning and design. It can be used in any process expected and reviewed in a timely manner for project planning and implementation. This paper focuses on the application process and method of HIA in community micro renewal. 


\subsection{Basic Process}

The process of health impact assessment applied to planning and design is basically the same, including three stages: assessment preparation stage, assessment analysis stage and project implementation stage.

\subsubsection{Evaluation preparation stage}

First of all, the government and the relevant research institutions should formulate the regional health community index system. index system of the building will provide comparative basis for subsequent evaluation, on the crosswise comparison between different areas and different community with longitudinal comparison of different periods of the same community provides guidance basis, For example, the health community index in Sydney, Australia, is constructed on the basis of Victoria community indicators, including health, safety and inclusiveness, cultural diversity, public participation, economic vitality and sustainable development, covering 101 indicators. Then, on the basis of healthy community indicators, the project is screened and evaluated to determine whether it needs HIA. The degree of impact of HIA on the project and the operability of specific implementation (Table 1). After screening, projects meeting the conditions enter the definition stage of HIA.

According to the literature and site conditions, the health impact logical framework was formulated, the aspects and data needed to be evaluated were summarized, and the assessment method, evaluation implementation personnel and assessment scheme were determined. Taking an example of the health impact assessment of neighbourhood community renewal of the eastern part of the San Francisco, under the background that the original point zoning did not have a positive impact on the community, in 2002 the planning department of San Francisco started the work of zoning for the eastern neighbourhood communities. The HIA was carried out to understand the potential impact of the zoning scheme on the community, and put forward suggestions for optimization and adjustment, so as to minimize the adverse impact of the design scheme on the health of the community population and maximize the beneficial impact. In the stage of preparation for assessment, they created a health development measurement tool (Figure 3) ; determined the development prospect of a healthy city; set 27 community health goals; developed more than 100 measurable indicators to measure the gap between reality and the goal; formulated index benchmark data to determine development goals; and developed a database of population health and influencing factors. Through network propaganda, government promotion and people's participation, an evaluation committee composed of 25 organizations or individuals has been established.

\begin{tabular}{|c|c|}
\hline Classification & Content \\
\hline Housing & $\begin{array}{l}\text { Affordability, Suitability, Physical hazards, Personnel composition, } \\
\text { Investment statu }\end{array}$ \\
\hline Air quality & Indoor and outdoor air pollutants, Smoke conditions \\
\hline Noise & Environmental noise, Occupational noise \\
\hline Security & $\begin{array}{l}\text { Violent crime, Property crime, Fire danger, Traffic Danger, Night } \\
\text { safety index }\end{array}$ \\
\hline Social networks & Contact friends and family \\
\hline Nutrition & Food cost, Food quality, Food safety, Access to food and distance \\
\hline Parks and green Spaces & Park and green space quality, Service, path \\
\hline $\begin{array}{l}\text { Personal goods and } \\
\quad \text { Services }\end{array}$ & $\begin{array}{l}\text { Quality and distance of financial institutions, Childcare services, } \\
\text { Health services }\end{array}$ \\
\hline Public service & Quality and distance of medical services \\
\hline Traffic & $\begin{array}{l}\text { The distance of go to work, purchase, services and education, by } \\
\text { non-motor vehicle travel, and by vehicle travel }\end{array}$ \\
\hline Social justice & $\begin{array}{l}\text { The proportion of low-income population, Education level, } \\
\text { Proportion of foreigners and residents' attitudes towards them }\end{array}$ \\
\hline
\end{tabular}




\begin{tabular}{cl}
\hline Livelihood & Employment status, Source of income, Welfare and Vacation, \\
& Hazards at work, Degree of freedom at work \\
Water quality & Pollutants in drinking water, Landscape water quality \\
Education & School quality, Distance from school \\
Public participation & Degree and quality of participation in public decision-making \\
\hline
\end{tabular}

Table 1. Determinants of community health in the health impact assessment

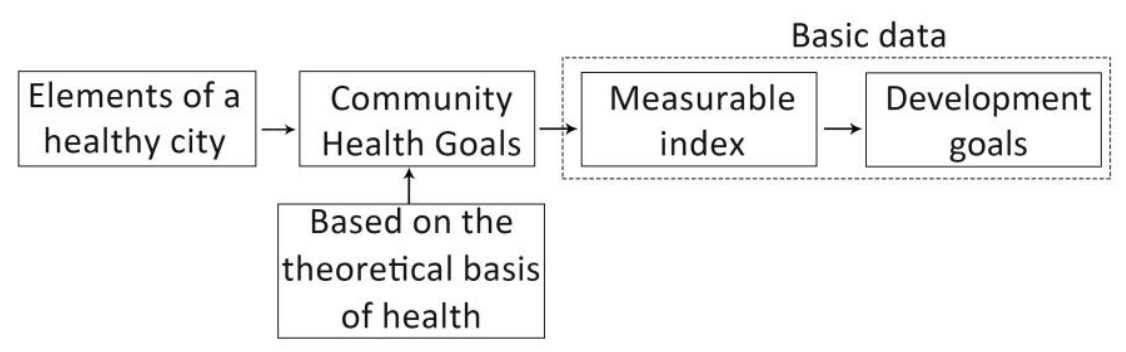

Figure 3. Health development measure tool structure diagram.

\subsubsection{Health impact assessment stage}

In this stage, based on the results of the assessment preparation stage, the potential health impact is quickly and deeply assessed through data, and the affected population and the prediction, degree and measures of health impact are analyzed. When evaluating the community, the assessment can be divided into two aspects: physical environment factors and residents' basic conditions. The physical environment factors mainly focus on the connection between the community and the surrounding urban space (public transport stations, market accessibility, surrounding green space distribution), internal road system and traffic facilities (riding route convenience, bicycle parking and car parking), community service facilities (public activity space, fitness and sports venues, distribution of shops, community residents' communication space) ) Building quality (safety and stability, building facade), green space quality (green space and plant distribution, plant species, growth, landscape effect), courtyard space (space layout, independent greening, landscape effect). The basic conditions of residents include age, physical condition, income, employment, daily life style (food procurement, sports and fitness methods and places, leisure and entertainment activities, etc.). The statistical analysis of data usually adopts extrapolation, HEAT (health economic assessment tool), contribution analysis, causal analysis and other methods.

\subsubsection{Design and Implementation stage}

According to the evaluation results, the corresponding suggestions and action plans are put forward for the planning and design project. Whether the project needs to be modified, the project is adjusted according to the evaluation results. If the project deviates from the community health needs, the alternative scheme is designed on the basis of the data, and the professional team is invited to report the scheme to the public and listen to the relevant departments, the public and the interests. We should pay attention to the public participation, adjust the project again combined with relevant opinions, and finally publish the planning and design results, and publicize and display in various channels. If the project enters the implementation stage, the implementation effect shall be tracked, monitored and evaluated, which can be divided into process evaluation, impact evaluation and result evaluation. If the project 
achieves the expected effect, the HIA shall be summarized and filed. If the expected effect is not achieved, based on the existing implementation, the reasons for the failure to reach the expected health impact shall be analyzed, and the retrospective evaluation shall be conducted after the transformation .

\section{Renovation of public space in Dashilan Community yard}

\subsection{General situation of Dashilan}

Located south of Tian 'anmen Square and west of Qianmen Avenue, The Dashilan area has a 600-year history of development. It is the central section of old Beijing and an important part of the south Central axis. There are altogether 9 communities in Dazhangan district. With the development of Beijing and the change of times, the old infrastructure, narrow public space and residential population pattern in Dazhangan district have accelerated the decline of the block and reduced the living satisfaction of the community residents. Dazhalan area in 1999 is listed as one of the Beijing old city historical protected areas, is listed as one of Beijing's first batch of historical and cultural blocks in 2015, as Dashilan area is getting increasing attention, the Dashilan updating plan is developed, several peripheral and internal important streets have been broaden and the population in Dashilan are relieved by voluntary retreating .Small-scale lively businesses are recommended. Among them, the 'top-down' renovating approach led by government enterprises ignores the key role played by residents in community, leading to low utilization rate of the updated site, while micro-renovation spontaneously formed by residents often fails to achieve the expected effect due to the lack of professional technical knowledge and support. While the hutong Green micro-renovation, Blue Bucket Plan, Hutong 2018 impression Experiment and other activities are carried out to jointly promote the improvement of neighbourhood environment and the revitalization of community culture through social individu alsand residents' participation, residents hope to carry out the renovation work of courtyard public space further.

Under the guidance of healthy cities, the impact of community renovation on people's health has attracted more and more attention. Under these circumstances, with the support of Dashilan Investment Co., Ltd. and Dashilan Community, the postgraduate students from The School of Landscape Architecture of Beijing Forestry University and the Xiangzhou Practice teamandconducted the health impact assessment of residents in Dashilan.

\subsection{Application of health impact assessment}

\subsubsection{Filtering and scope definition}

After studying the distribution of residents and the use of public space in Dashilan, we found that the population structure shares the same characteristics with people with social difficulties. the migrant population in Dashilan accounts for $29 \%$ of the resident population; The vulnerable people are relatively concentrated; The income level and the consumption level of residents is low, Quantities of residents living on less than 8 yuan per day; People performed high prevalence of cardiovascular and cerebrovascular diseases; Due to the narrow space in the block, the residents in the community lack physical exercise. The community renovation HIA study covered 34 streets in The Dashilan area (Figure 4). The purpose of this HIA assessment is to highlight the potential positive health impacts of public space in the courtyard and to avoid potential obstacles with negative impacts in the project. It will be a positive promotion and of great reference for the future development of the healthy community indicator system constructing in the district. 


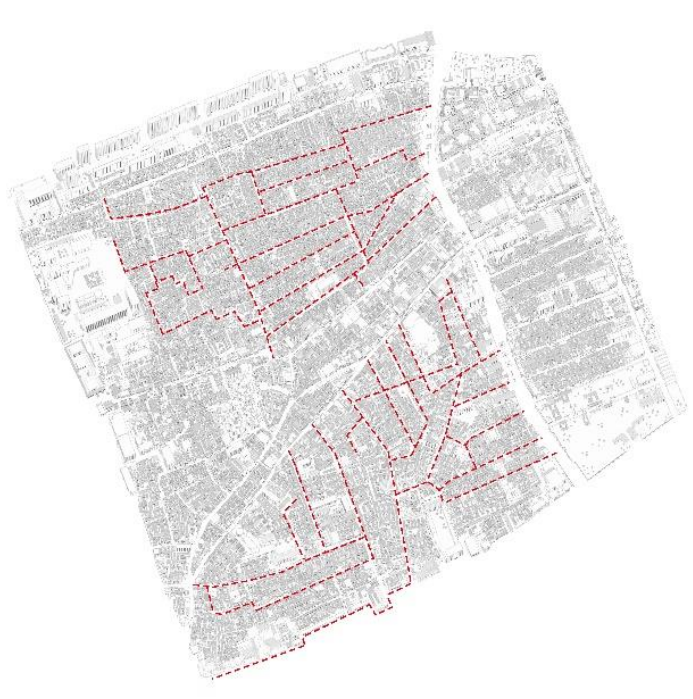

Figure 4. Research scope and research route.

We've made a survey of 307 households in the community to acquire the data for evaluation (table 2), and according to community health determinants, with the opinions of experts who specialized in sports medicine, landscape architecture, plant expert and the community , we draw a conclusion about elements that determines community health: social networks, social justice, livelihoods, personal basic situation, the green space and planting situation, mitigation measures, research task and method. Meetings were held in communities to negotiate about the research plan.

\begin{tabular}{|c|c|c|c|c|c|}
\hline \multirow{2}{*}{$\frac{\text { Project }}{\text { Age }}$} & \multicolumn{5}{|c|}{ Statistical Results } \\
\hline & below 30 & $30-45$ & $45-60$ & $60-75$ & above75 \\
\hline & $5.20 \%$ & $14.00 \%$ & $25.10 \%$ & $39.40 \%$ & $16.30 \%$ \\
\hline \multirow[t]{2}{*}{ Living } & Living alone & $\begin{array}{l}\text { Living with } \\
\text { family }\end{array}$ & & & \\
\hline & $15.60 \%$ & $84.40 \%$ & & & \\
\hline \multirow[t]{2}{*}{ Marital Status } & Married & Unmarried & Divorced & Widowed & \\
\hline & $81.70 \%$ & $8.80 \%$ & $0.70 \%$ & $8.80 \%$ & \\
\hline \multirow[t]{2}{*}{ Education } & $\begin{array}{l}\text { Junior High } \\
\text { school and } \\
\text { below }\end{array}$ & High school & University & & \\
\hline & $45.90 \%$ & $38.80 \%$ & $15.30 \%$ & & \\
\hline \multirow[t]{2}{*}{ Work Status } & Retired & On the Job & & & \\
\hline & $71.70 \%$ & $28.30 \%$ & & & \\
\hline \multirow[t]{2}{*}{ Income } & below 1000 & $1000-3000$ & $3000-5000$ & above5000 & \\
\hline & $5.90 \%$ & $27.00 \%$ & $48.20 \%$ & $18.90 \%$ & \\
\hline \multirow[t]{2}{*}{ Idle Time } & less than $2 \mathrm{~h}$ & $2 h-4 h$ & $\begin{array}{l}\text { greater } \\
\text { than } 4 \mathrm{~h}\end{array}$ & & \\
\hline & $6.80 \%$ & $26.80 \%$ & $66.40 \%$ & & \\
\hline \multirow[t]{2}{*}{$\begin{array}{l}\text { Weekly Exercise } \\
\text { Frequency }\end{array}$} & No Exercise & less than 3 times & $\begin{array}{l}\text { 3times - } \\
\text { 5times }\end{array}$ & $\begin{array}{l}\text { more than } 5 \\
\text { times }\end{array}$ & \\
\hline & $15.00 \%$ & $30.10 \%$ & $16.30 \%$ & $38.60 \%$ & \\
\hline \multirow[t]{2}{*}{$\begin{array}{c}\text { The length of each } \\
\text { exercise }\end{array}$} & $\begin{array}{l}\text { less than } 30 \\
\text { minutes }\end{array}$ & $\begin{array}{l}30 \text { minutes }-60 \\
\text { minutes }\end{array}$ & $\begin{array}{l}60 \text { minutes } \\
\text { or more }\end{array}$ & & \\
\hline & $39.10 \%$ & $37.50 \%$ & $23.40 \%$ & & \\
\hline $\begin{array}{l}\text { Standard for more } \\
\text { than } 30 \text { minutes } 5\end{array}$ & Acceptable & Unacceptable & & & \\
\hline
\end{tabular}


days a week
$47.90 \%$
$52.10 \%$

Know plants are

good for your health or not

Yes No

$92.20 \% \quad 7.80 \%$

$\begin{array}{ccc}\begin{array}{c}\text { Plant planting or not } \\ \text { planting }\end{array} & \text { Yes } & \text { No } \\ & 90.60 \% & 9.40 \%\end{array}$

The frequency of gardening activities

$\begin{array}{cccc}\text { No gardening } & \text { less than } 3 \text { times } & 3-5 \text { times } & \begin{array}{c}\text { more than } 5 \\ \text { times }\end{array} \\ 9.40 \% & 21.80 \% & 11.10 \% & 57.70 \%\end{array}$

The type of plant grown

Fruits and vegetables class

$41.40 \%$

Self physical
condition identified

Communication

with neighbors

\begin{tabular}{cc} 
& $19.90 \%$ \\
\hline & Physical condition \\
\hline
\end{tabular}

$\begin{array}{lc} & 3.30 \% \\ \text { Mental health status } & \text { Anxiety } \\ & 4.50 \%\end{array}$

\section{Pure ornamental class}

\section{$58.60 \%$}

Table 2. Evaluate the results of the required data

\subsubsection{Evaluation and analysis}

The HIA assessment analysis is based on the conclusions made by previous researchers, linking health improvement methods to health outcomes, and generates a causal-relationship analysis, also evaluates the strategies to determine the relationship between the interventions in the strategies and health. Thus, The potential influence of public space on physical activity, social cohesion and scenery greening in Dashilan community courtyard was determined.

1) Sports activities and greening of the courtyard public space 
In order to increase the open space in the courtyard and the frequency of gardening activities, we claimed that the main aim of the renovation is creasing sports activities. It's investigated that providing green components can promote the district's physical activities and social in teractions; More than 30 minutes' moderate exercise of gardening activities can achieve fitness like other forms of sports; the increase in physical activity is associated with many positive health outcomes, including the ability to control the weight, improve the mobility of the elderly, decrease depression and anxiety, prevent bad effects of high blood pressure and diabetes. The research results show that the Dashilan community residents' exercising frequency did not meet the standard suggested by science institutions, which is '5dayworkers should at least take 30 minutes of exercises per week'. However, existing public green space is far from enough to reach the national residential land balance control index:7.5-18\%, and the surrounding urban roads of community are occupied, with no space for green road constructing. Data mentioned above indicated that the community needs additional space and green land to increase physical exercise. The greening of the public space in the courtyard is meaningful, on the one hand, it increases the green rate of the community, and on the other hand, it can improve the residents' gardening activities to achieve the positive effect of physical exercise.

In order to make the residents achieve enough exercise and the prescribed exercise duration after the renovation, the following strategies are proposed: increasing the distance between water source and planting area in order to make residents carry watering cans for exercise; Controling the plants' height and making residents raise the watering can for watering exercise; Various planting forms can be combined to ensure sufficient planting quantities and increase the daily gardening time; plants with features of fast growth, easy branching and fruiting, are used for plant sorting, pot removing and picking.

2) Enhancing social cohesion

Research has shown that public Spaces can enhance social cohesion and collective efficacy, and that social networks and interactions can prolong people's life, improve mental health, and reduce crime and i harm. Social relationship is the source of emotional and material support. whatever it is providing or receiving help, will release social stress, prevent loneliness, and boost self-esteem. Improving yard public space and creating a pleasant outdoor space, can enhance the communications of inhabitants, which may include the experience of planting and seed exchanging This makes neighbourhood harmonious and people get a sense of pride and happiness, otherwise it may help migrant workers get on with the community life and increase the sense of belonging. The harmony of the neighbourhood increases the possibility of community activities. 
In order to establish good social cohesion in the updated public space of the yard, the following strategies are proposed: design small spaces for gathering and communicating in the courtyard, such as small seats, message boards, chess tables, public goods using area, etc. so as to increase and expand various community activities, such as sharing planting experience, holding 'plant adoption' activities, and give full play to the initiative of community.

3) Increase scenery greening

Increasing the greening rate in the community means improving the liveability of the community, fulfilling the satisfaction of residents, improving the health and safety. People who live in a green environment have better health status than those who don't. Exposure to green plants makes less stress in daily life and improves people's concentration, productivity and health recovery. Taking advantage of cheap plant can reduce the cost of renovating. Also, utilizing native ,easily-living or edible plants, can provide more scenic ornamentals, safe food for residents, and improve the satisfaction, the sense of accomplishment, self-confidence, and economic values of gardening activities.

In order to make the public space of the courtyard a natural and green environment after renovating, the following strategies are proposed: use more green plants for renovating to improve the scenery effect, such as planting climbing plants, hanging plants and planting containers on the wooden frame during reconstructing the opposite side; Use waste materials as containers for planting, and picking easily-living , edible plants can effectively reduce the cost of construction and maintenance. Also, strengthen renovation of the vertical direction of the yard, , in order to save more available space.

\subsubsection{Evaluation Conclusions}

This study evaluated the potential positive impact on health of public space renovation in Dashilan community yard through HIA and discuss about the methods and strategies to achieve positive impact. The renovation of the public space in the yard has increased the greening rate of the community. The updated courtyard space has increased manual activities, enhanced social cohesion, and increased scenery greening, which are effective ways to improve health quality. The positive health effects of the renovation of public Spaces in community courtyards include the reduction of obesity, diabetes and cardiovascular diseases, also the improvement of mental health. Through the renovation, Many ways of $i$ improving health quality are accessible.

\subsection{Deficiencies of the study}

Currently, researches of Health impact assessment system hasn't made effective progress in China. HIA was first used in the update work of Dashilan community yard and there are many shortcomings: research contents of HIA in community-updating focus on public space of community yard, and ignore the research of streets, public space of blocks and other aspects, which is incomprehensive. Thus, limited conclusions were made in this kind of research; There is no cooperation between the local health department and the government and that leads to the lack of advice from local health department in the research process; Due to the lack of research funds, this health impact assessment was carried out during the pre-study stage of the project, and the HIA comprehensive assessment need to proceed. 


\section{Conclusion}

HIA provides an effective way of connecting public health problem with the theory and practice of community updates, community updates utilized in HIA can not only improve the physical health of community residents, but also establish cooperation relationship between various departments. Furthermore, It enhances the public participation, and lay the first stone for the future community work and activities. To some extents, it serves as a tool of preventing social and health inequities.

\section{References}

Li Min, Ye Changdong. Threshold criteria and global distribution characteristics of high-density cities [J]. World geography research,2015,24(01):38-45.

Maigeng Zhou, et al. Mortality, morbidity, and risk factors in China and its provinces, 1990-2017: a systematic analysis for the Global Burden of Disease Study 2017. Lancet, Published Online June 24, 2019

Ma Ming, CAI Zhenyu. Research on urban Green open Space from the Perspective of Health -- Health Utility and Design Response [J]. Chinese landscape architecture,2016,32(11):66-70.

Norris T,Pittman M. The Healthy Communities Movement and the Coalition for Healthier Cities and Communities[J].Public Health Reports (1974-),2000,115(2/3):118-124.

The WHO Regional Office for Europe.Urban health-Phase VI (2014-2018) of the WHO European Healthy Cities Network goalsandrequirements [EB/OL ] . [2019-01-07 ] .http : //www.eu ro.who.int/en/health - topics/environment - and - health/urban - health/ publications/2014/phase - vi 2014-2018-of-the-who-european- healthy-cities-network-goals-and-requirements.

Li Min, Ye Changdong. Threshold criteria and global distribution characteristics of high-density cities [J]. World geography research,2015,24(01):38-45.

Gongwei. Renewal of public space in old communities under the guidance of 'Open Community' -- A Case study of Tiantong Yuan in Beijing [J]. Urban development studies,2019,26(11):66-73.

Hou Xiaolei. Discussion on micro-renewal of urban public space based on community building [J]. Landscape architecture,2019,26(06):8-12.

ROSS C, ORENSTEIN M, BOTCHWEY N. Health impact assessment in the United States[M]. New York: Springer, 2014.

Weng Shuncan, Chen Chun, Yu Li. Experience of healthy community construction in Australia and its implications for China [J]. Urban architecture,2019,16(04):77-82.

Research Group of 'Beijing Urban Corner Investigation', Beijing Academy of Social Sciences. Investigation of Urban Corners in Beijing [J]. Book Abstract,2005(11):13-16.

M. Smith, J. Hosking, A. Woodward 'Systematic literature review of built environment effects on physical activity and active transport -- An update and new findings on health equity', International Journal of Behavioral Nutrition and Physical Activity, 14 (2017), p. 158, 10.1186/s12966-017-0613-9

The Benefits of Gardening for Older Adults: A Systematic Review of the Literature

Physical Activity and Health: A Report of the Surgeon General.Available at: http://www.cdc.gov/nccdphp/sgr/sgr.htm

The East Bay Greenway Health Impact Assessment 
Sherer, P.M., The Benefits of Parks: Why America Needs More City Parks and Open Space. 2006, The Trust for Public Land.

Hammack, P.L., et al., Social support factors as moderators of community violence exposure among inner-city African American young adolescents. J Clin Child Adolesc Psychol, 2004. 33(3): p. 450-62.

Cohen, S., L.G. Underwood, and B.H. Gottlieb, eds. Social support measurement and intervention. 2000, Oxford University Press: New York.

Maas, J., et al., Green space, urbanity, and health: how strong is the relation? J Epidemiol Community Health, 2006. 60(7): p. 587-92.

Maller, C., et al., Healthy nature healthy people: 'contact with nature' as an upstream health promotion intervention for populations. Health Promot Int, 2006. 21(1): p. 45-54. 